\title{
Macro and Micro Models of Milling of Carbon Fiber Reinforced Plastics using Fem
}

\author{
Y.L. He, Y.L. Liu, J.G. Gao \\ Key laboratory of contemporary design and integrated manufacturing technology \\ Ministry of Education, Northwestern Polytechnical University \\ ShaanXi, China
}

\begin{abstract}
With wide application of carbon fiber reinforced plastics (CFRP) in aeronautic and astronautic products, the machining of FRP, particularly by means of milling is gaining more and more attention. In order to analysis the milling mechanism and process, both macro-mechanical and micromechanical 3-D finite element (FE) models were developed in this paper for machining simulation of unidirectional CFRP. Three-dimensional Hashin criterion is used for material damage prediction. The milling force simulated by two models was analyzed. The delamination is also simulated based on cohesive element in micro-mechanical model. The simulation result shows that the milling force and the delamination increase with increasing feeding rate, and decrease with an increase of the cutting speed, as is consistent with experimental observations.
\end{abstract}

Keywords-CFRP, milling; FEM; cohesive element

\section{INTRODUCTION}

With advantages of high strength and high specific stiffness, Carbon Fiber Reinforced Plastics (CFRP) has been widely used in aeronautics, astronautics, medical science, sports, and other area. However, CFRP is also a typical difficult-to-machine material due to its heterogeneity and anisotropy of mechanical properties. In order to improve the machining efficiency and reduce the machining damage, some research work has been conductedthrough experimentto study the process of CFRPmilling during past years. The characteristic of milling force, roughness and delamination were investigated [1-2].

In recent years, with the development of computer technology, finite element simulation is considered to be an effective tool to study the cutting process. A good FEM model can not only simulate the cutting process, but also the distribution of the cutting force, torque and final damage, which may help to reveal the cutting mechanism. During past years, quite a few FEM model for FRP machining was developed, mainly for orthogonal cutting and drilling process. Mofid and Zhang [3] built a two-dimensional finite element model for cutting composite materials. The material was modeled as equivalent homogenous anisotropic material and Tasi- Hill failure criterion was used. The simulation results agreeclosely to the experimental results. L.M.P.Durao et al. [4] built a three-dimensional model of drilling carbon fiber composite materials. The carbon fiber composite was modeled by successive layers, allowing the use of different stacking sequences. The tool was modeled as a rigid body, and different tool geometries were compared.

Despite existing work, there till exits no FE model for CFRP milling simulation in literature. This paper has established a macro FEM model and a micro mechanical model for milling CFRP.The milling force and delamination during milling processare investigated.

\section{NumericAl MODELLING OF MiLLING IN CFRP LAMINATE}

\section{A. Geometry and Meshing}

TheCFRP workpiece in both models has a dimensionof $30 \mathrm{~mm} \times 15 \mathrm{~mm} \times 0.56 \mathrm{~mm}$. The whole workpieceismodeled as homogenous equivalent material in macro model. However in micro model, the workpiece is composed of twoseparated plies with an individual ply thickness of 0.26 $\mathrm{mm}$. A cohesive zone with a thickness of $0.04 \mathrm{~mm}$ is placed between two plies. In order to predict the effect of cutting parameters on milling of UD CFRP, a three-flute end mill, which has a $45^{\circ}$ helix angle and $10 \mathrm{~mm}$ diameter, is modeled and imported into the FE simulation model. To reduce the computing complexity, the end mill is modeled as a rigid body. Figure 1 shows the two FE models.

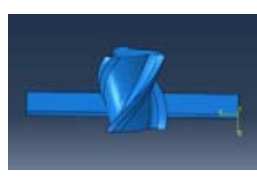

(a)

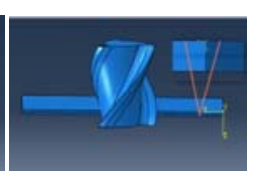

(b)
FIGURE I. FEM MODELS : (A) MACRO MODEL (B) MICRO MODEL.

Reasonable meshing could reduce the computation time and increase simulation accuracy. As the end mill is relatively complex in structure, free meshing technique is applied for the tool. The end mill is meshed with 4-node, 3D rigid elements (C3D4). The CFRP laminate is meshed with 8-node, 3D brick elements (C3D8R).For the micro model, each ply is meshed with one layer of elements in thickness. The cohesive zone is modeled with cohesive elements (COH3D8) for the simulation of delamination. The finalworkpiece mesh is composed of 11850 elements in macro model and 15116 elements in micro model. The tool contains 42939 elements in both models. The element size is around $200 \mu \mathrm{m}$. 


\section{B. Tool-Work Piece Contact}

In this paper, Coulomb friction model given in Eq.1 [5] is used to simulate frictional effects between the tool and workpiece.

$$
\tau_{n}=\mu \sigma_{n}
$$

where $\tau_{n}$ denotes frictional stresses, $\sigma_{n}$ denotes normal stresses, and $\mu$ denotes a constant friction coefficient. The coefficient of friction is set equal to 0.3 in the model. General contact algorithm in ABAQUS/Explicit is used in this simulation.

\section{Boundary Conditions and Loading}

According to the actual cutting condition, the workpiece is completely fixed on both ends. The end mill is constrained so as to rotate with its axis and moved along the feeding direction. To study the effect of cutting parameters on milling, the combination of the cutting parameters is listed in table 1 .

TABLE I . CUTTING PARAMETERS USED IN THE MILLING OF CFRP.

\begin{tabular}{crcl}
\hline Spindle speed $(\mathrm{rpm})$ & 1500 & 2000 & 3000 \\
\hline Feed rate $(\mathrm{mm} / \mathrm{min})$ & 180 & 300 & 450 \\
\hline
\end{tabular}

\section{Constitutive Material Modelling}

Constitutive material model of each ply: Homogenous material with orthogonal anisotropicbehavioris assumed for the whole workepiece in macro model and also for each ply in micro model. The stress-strain relations could be expressed as:

$$
\left[\begin{array}{l}
\varepsilon_{11} \\
\varepsilon_{22} \\
\varepsilon_{33} \\
\gamma_{12} \\
\gamma_{13} \\
\gamma_{23}
\end{array}\right]=\left[\begin{array}{cccccc}
\frac{1}{E_{1}} & -\frac{v_{12}}{E_{2}} & -\frac{v_{13}}{E_{3}} & 0 & 0 & 0 \\
-\frac{v_{21}}{E_{1}} & \frac{1}{E_{2}} & -\frac{v_{23}}{E_{3}} & 0 & 0 & 0 \\
-\frac{v_{31}}{E_{1}} & -\frac{v_{32}}{E_{2}} & \frac{1}{E_{3}} & 0 & 0 & 0 \\
0 & 0 & 0 & \frac{1}{G_{23}} & 0 & 0 \\
0 & 0 & 0 & 0 & \frac{1}{G_{31}} & 0 \\
0 & 0 & 0 & 0 & 0 & \frac{1}{G_{12}}
\end{array}\right]\left[\begin{array}{l}
\sigma_{11} \\
\sigma_{22} \\
\sigma_{33} \\
\sigma_{12} \\
\sigma_{13} \\
\sigma_{23}
\end{array}\right]
$$

Constitutive damage model of each ply: The damage criterion is based on 3D Hashin' theory [6]. There are four failure modes listed as below.

Fiber tension $\left(\sigma_{11}>0\right)$

$$
\left(\frac{\sigma_{11}}{X_{t}}\right)^{2}+\frac{1}{S_{12}^{2}}\left(\sigma_{12}^{2}+\sigma_{31}^{2}\right)^{2} \leq 1
$$

Fiber compression $\left(\sigma_{11} \leq 0\right)$

$$
\left(\frac{\sigma_{11}}{X_{C}}\right)^{2} \leq 1
$$

Matrix tension $\left(\sigma_{22}+\sigma_{33}>0\right)$

$$
\frac{1}{Y_{t}^{2}}\left(\sigma_{22}+\sigma_{33}\right)^{2}+\frac{1}{S_{23}^{2}}\left(\sigma_{23}^{2}-\sigma_{22} \sigma_{33}\right)+\frac{1}{S_{12}^{2}}\left(\sigma_{12}^{2}+\sigma_{31}^{2}\right) \leq 1
$$

Matrix compression $\left(\sigma_{22}+\sigma_{33} \leq 0\right)$

$$
\begin{aligned}
& \frac{1}{Y_{C}}\left[\left(\frac{Y_{C}}{2 S_{23}}\right)^{2}-1\right]\left(\sigma_{22}+\sigma_{33}\right)+\frac{1}{4 S_{23}^{2}}\left(\sigma_{22}+\sigma_{33}\right)^{2}+\frac{1}{S_{23}^{2}}\left(\sigma_{23}^{2}-\sigma_{22} \sigma_{33}\right)+ \\
& \frac{1}{S_{12}^{2}}\left(\sigma_{12}^{2}+\sigma_{31}^{2}\right) \leq 1
\end{aligned}
$$

whereXt, Xc, Yt, Yc, S12, S23 denotes the CFRP materials engineering constants respectively.

The material properties of CFRP are listed in Table 2 [5].

The material behavior and three-dimensional Hashin failure criterion areimplemented in material subroutine (VUMAT) in ABAQUS.

Constitutive material model of cohesive zone: To simulate the cohesive zone, traction-separation cohesive material model is used. The stress-strain relations [5] in the zone could be explained as:

$$
\left[\begin{array}{l}
\sigma_{n} \\
\sigma_{s} \\
\sigma_{t}
\end{array}\right]=\left[\begin{array}{ccc}
K_{n n} & 0 & 0 \\
0 & K_{s s} & 0 \\
0 & 0 & K_{t t}
\end{array}\right]\left[\begin{array}{l}
\varepsilon_{n} \\
\varepsilon_{s} \\
\varepsilon_{t}
\end{array}\right]
$$

Constitutive damage model of cohesive zone: The quadratic nominal-stress criterion [6-7] is used corresponding to traction-separation model.

\begin{tabular}{|c|c|c|c|c|c|}
\hline $\begin{array}{l}E_{1}(\mathrm{MP} \\
\text { a) } \\
11200 \\
0\end{array}$ & $\begin{array}{l}\mathrm{E}_{2}(\mathrm{MP} \\
\text { a) } \\
8200\end{array}$ & $\begin{array}{l}\mathrm{E}_{3}(\mathrm{MP} \\
\text { a) } \\
8200\end{array}$ & $\begin{array}{l}\mathrm{G}_{12}(\mathrm{M} \\
\mathrm{Pa}) \\
4500\end{array}$ & $\begin{array}{l}\mathrm{G}_{13}(\mathrm{M} \\
\mathrm{Pa}) \\
4500\end{array}$ & $\begin{array}{l}\mathrm{G}_{23}(\mathrm{M} \\
\mathrm{Pa}) \\
3000\end{array}$ \\
\hline $\begin{array}{r}\boldsymbol{v}_{12} \\
0.3\end{array}$ & $\begin{array}{l}v_{13} \\
0.3^{3}\end{array}$ & $\begin{array}{l}v_{23} \\
0.4\end{array}$ & $\begin{array}{l}\mathrm{X}_{\mathrm{t}}(\mathrm{MPa} \\
{ }^{1900} \\
\end{array}$ & $\begin{array}{l}\mathrm{X}_{\mathrm{c}}(\mathrm{MP} \\
\mathrm{a}) \\
1000\end{array}$ & $\begin{array}{l}\mathrm{Y}_{\mathrm{t}}(\mathrm{MPa} \\
84\end{array}$ \\
\hline $\begin{array}{l}\mathrm{Y}_{\mathrm{c}}(\mathrm{MP} \\
\text { a) } \\
250\end{array}$ & $\begin{array}{l}\mathrm{Z}_{\mathrm{t}}(\mathrm{MP} \\
\text { a) } \\
84\end{array}$ & $\begin{array}{l}\mathrm{Z}_{\mathrm{c}}(\mathrm{MP} \\
\text { a) } \\
250\end{array}$ & $\begin{array}{l}\mathrm{S}_{12}(\mathrm{MP} \\
\mathrm{a}) \\
60\end{array}$ & $\begin{array}{l}\mathrm{S}_{23}(\mathrm{MP} \\
\mathrm{a}) \\
110\end{array}$ & \\
\hline
\end{tabular}

The damage initiation condition is represented as below.

$$
\left[\frac{t_{n}}{t_{n}^{0}}\right]+\left[\frac{t_{s}}{t_{s}^{0}}\right]+\left[\frac{t_{t}}{t_{t}^{0}}\right]=1
$$

where $t_{n}, t_{s}, t_{s}$ represent the instantaneous components of normal and shear tractions in the cohesive zone, while $t_{n}^{0}$, $t_{s}^{0}, t_{t}^{0}$ are the peak values.

TABLE II . MATERIAL PROPERTIES OF CFRP. expression:

$$
\left[\frac{G_{n}}{G_{n}^{c}}\right]+\left[\frac{G_{s}}{G_{s}^{c}}\right]+\left[\frac{G_{t}}{G_{t}^{c}}\right]=1
$$

where $G_{n}, G_{S}, G_{t}$ are the instantaneous fracture 
energies in normal, and shear directions, while $G_{n}^{c}, G_{s}^{c}, G_{t}^{c}$ refer to the critical fracture energies. The properties of cohesive zone are listed in Table 3 [5].

TABLE III. Material properties of cohesive zone.

\begin{tabular}{llllll}
\hline $\mathrm{t}_{\mathrm{n}}^{0}(\mathrm{MPa})$ & $\mathrm{t}_{\mathrm{s}}^{0}(\mathrm{MP})$ & $\mathrm{t}_{\mathrm{t}}^{0}(\mathrm{MPa})$ & $\mathrm{G}_{\mathrm{n}}^{\mathrm{c}}(\mathrm{N} / \mathrm{mm})$ & $\mathrm{G}_{\mathrm{s}}^{\mathrm{c}}(\mathrm{N} / \mathrm{mm})$ \\
$\mathrm{G}_{\mathrm{t}}^{\mathrm{c}}(\mathrm{N} / \mathrm{mm})$ & & & & & \\
60 & 110 & 110 & 0.33 & 1.209 & 1.209 \\
\hline
\end{tabular}

\section{RESUlTS AND DisCUSSION}

\section{A. Analysis of Force}

In the milling process, the cutting forces consist of two components: Fx and Fy. Fx is perpendicular to the feed direction ( $\mathrm{X}$ axis direction). Fy is parallel to the feed direction ( $\mathrm{Y}$ axis direction). Figure 2 (a) and (b) shows Fx and Fy of both models at $180 \mathrm{~mm} / \mathrm{min}$ feed rate and 3000 rpm spindle speed.

As can be observedfrom Fig. 2 (a) and (b), macro model predicts higher cutting forces than micro model forboth Fx and Fy. This is because delamination occurred due to the failure of cohesive elements in the micro model, so the structure is degraded.

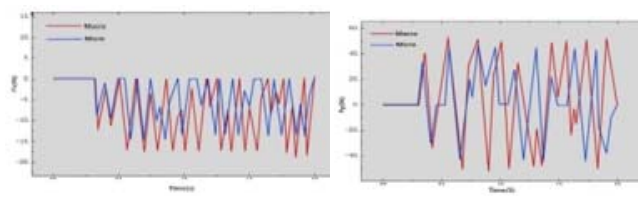

(a)

(b)

FIGURE II. Milling force (a) Fx (b) Fy (n=3000 rpm f=180/min).

Figure 3 (a) shows the effect of cutting parameters on the average maximum Fx of the micro model. The micro model estimates Fx between 14.5 and $24.1 \mathrm{~N}$ depending on the cutting parameters. The obtained results show that Fx increases with the increasing feed rate. It can be observed from Fig. 3 (a), the Fx is lowest at the feed rate of 180 $\mathrm{mm} / \mathrm{min}$ and highest at feed rate of $450 \mathrm{~mm} / \mathrm{min}$ at various spindle speed. It is predicted that $150 \%$ higher feed rate led to an increase of Fxbetween 19.1\% and $37.7 \%$ depending on the spindle speed. Figure 3 (a) also shows thatFx decreases with increasing spindle speed. It is observed that $100 \%$ increase in the spindle speed causes a fall in Fx between $10.7 \%$ and $22.4 \%$ depending on the feed rate.

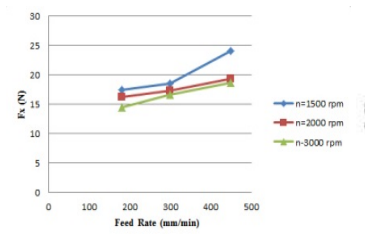

(a)

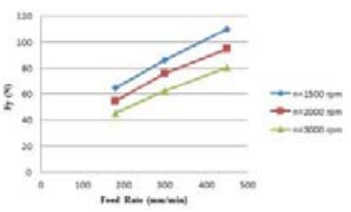

(b)

FIGURE III. EFFECTS OF CUTTING PARAMETERS ON (A) FX (B) FY.
Figure 3 (b) shows the average maximum Fy in the micro model corresponding to different cutting parameters. The Fy is estimated between 45.2 and $109.8 \mathrm{~N}$ in the micro model at various cutting parameters. From figure 3 (b), it is observed Fy increases with the increasing feed rate, and decreases with the increasing spindle speed, as is the same as the case of Fx. It is noticed that $150 \%$ higher feed rate resulted to an increase inFy between $67 \%$ and $78.1 \%$ depending on the spindle speed. It can be also observed that when the spindle speed increases $100 \%$,Fy decreased between $26.7 \%$ and $30 \%$ depending on the feed rate. The simulation is consistent with the experimental observation [8].

\section{B. Analysis of Delamination}

Figure 4 (a) shows the delamination occurred in the micro model. The delamination factor (FD) is used to describe the degree of damage on the workpiece, as given in Eq.10 [8].

$$
F_{D}=\frac{W_{\max }}{W}
$$

WhereWmaxis the width of maximum damage, and $\mathrm{W}$ the nominal width of the cut, as showed in Figure 4 (b).

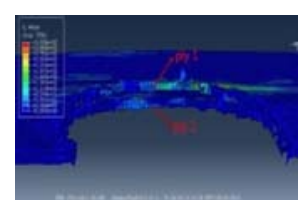

(a)

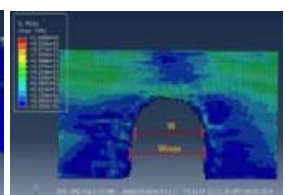

(b)
FIGURE IV. (A) DELAMINATION IN THE MICRO MODEL (B) FD.

Figure 5 shows delamination factor (FD) under different cutting conditions. It can be observed that the delamination factor decreases with increasing spindle speed and increases with increasing feed rate. When the feed rate increases $150 \%$, the delamination factor increases between $22.8 \%$ and $28 \%$, whereas the increase of spindle speed by $100 \%$ causes the reduction of the delamination factor between $22 \%$ and $24.8 \%$ depending on the cutting parameters. The simulation of delamination is also consistent with the experimental observation [9].

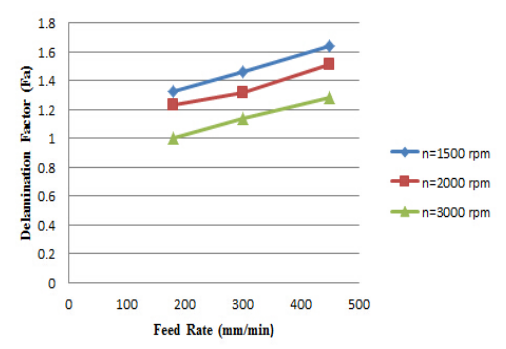

\section{FIGURE V.EFFECTS OF CUTTING PARAMETERS ON FD.}

\section{CONCLUSION}

In this paper two 3D finite element (FE) models are developed based on Lagrangian formulation tosimulatethe milling process of unidirectional CFRP.The results show that both $\mathrm{F}_{\mathrm{x}}$ and $\mathrm{F}_{\mathrm{y}}$ in the macro model are larger than those 
in the micro model, due to the delamination mechanism in the micro model. The results also show that both the milling force and delamination increase with the increasing feed rate, and decrease with the increasing spindle speed.

\section{ACKNOWLEDGEMENTS}

This work is supported by the 111 Project (Grant No.B13044).

\section{REFERENCE}

[1] Karpat Y, Bahtiyar O, Değer B. Milling force modelling of multidirectional carbon fiber reinforced polymer laminates. Procedia CIRP, 1, pp. 460-465, 2012.

[2] Hintze W, Hartmann D. Modeling of Delamination During Milling of Unidirectional CFRP. Procedia CIRP, 8, pp. 443-448, 2013.

[3] Mahdi M, Zhang L. A finite element model for the orthogonal cutting of fiber-reinforced composite materials. Journal of materials processing technology, 113(1), pp.373-377, 2001.

[4] Durao L M P, De Moura M, Marques A T. Numerical simulation of the drilling process on carbon/epoxy composite laminates. Composites Part A: Applied Science and Manufacturing, 37(9), pp.1325-1333, 2006.

[5] Isbilir O, Ghassemieh E. Finite element analysis of drilling of carbon fibre reinforced composites. Applied Composite Materials, 19(3-4), pp.637-656, 2012.

[6] XiaoQi Xiang. Finite Element Simulation of 3D Drilling in CFRP Composite and AluminiumStack. Thesis submitted to the University of Sheffield in partial fulfillment of the requirements for the degree of Master of Science (Research), 2011.

[7] Phadnis V A, Makhdum F, Roy A, et al. Drilling in carbon/epoxy composites:Experimental investigations and finite element implementation. Composites Part A: Applied Science and Manufacturing, 47,pp.41-51,2013.

[8] Davim J P, Reis P.Damage and dimensional precision on millingcarbonfiber-reinforced plastics using design experiments. Journal of Materials Processing Technology,160,pp. 160-167, 2005.

[9] Nor Khairusshima M.K, Che Hassan, C.H, Jaharah A.G, etc. Effect of chilled air on tool wear and workpiece quality during milling of carbon fibre-reinforced plastic.Wear, 302,pp.1113-1123, 2013. 